\title{
FEATURES ASSOCIATED WITH THE DEVELOPMENT OF NON-MOTOR MANIFESTATIONS IN PARKINSON'S DISEASE
}

\author{
Carlos Juri', Paola Viviani', Pedro Chaná-3
}

\begin{abstract}
Parkinson's disease (PD) is a neurodegenerative disorder, predominantly characterized by the presence of motor symptoms. However, the non motor manifestations (NMM) are a frequent complaint in the PD patients. There is a lack of information about the risk factors associated with the NMM in these patients. The aim of this study is to evaluate the prevalence of the more common NMM in a population of PD patients and to determine the features associated with its development. We studied 124 ambulatory PD patients. NMM were defined by the presence of neuropsychiatric manifestations, cognitive disorder, autonomic dysfunction or sleep related problems. In a multivariate analysis we found that the years of evolution of the PD and the presence of cognitive dysfunction are the risk factors for the neuropsychiatric and autonomic manifestations, whereas axial impairment is a risk factor for cognitive disorders and dyskinesias is for sleep related problems. In conclusion, this study shows that the features related to the PD progression appear as the main risk factors associated with NMM.
\end{abstract}

KEY WORDS: Parkinson's disease, non motor manifestations.

\section{Factores asociados con el desarrollo de complicaciones no motoras en la enfermedad de Parkinson}

Resumen - La enfermedad de Parkinson (EP) es un trastorno neurodegenerativo, caracterizado predominantemente por la presencia de sintomas motores. No obstante, la presencia de manifestaciones no motoras (MNN) son frecuentes en los pacientes con EP. Existe escasa información sobre los factores de riesgo asociados con la aparición de MNN en dichos pacientes. El objetivo de este estudio fue evaluar la prevalencia de las MNN más comunes en una población de pacientes portadores de EP y determinar los factores de riesgo asociados con su aparición. Estudiamos 124 pacientes portadores de EP atendidos en forma ambulatoria. La presencia de MNN fue definida por la aparición de manifestaciones neuropsiquiátricas, trastorno cognitivo, disfunción autonómica o alteraciones del sueño. En el análisis multivariado encontramos que los años de evolución de la EP y la presencia de disfunción cognitiva son los principales factores de riesgo para las manifestaciones neuropsiquiátricas y autonómicas, mientras que el compromiso axial es el mayor factor de riesgo para la aparición de manifestaciones cognitivas y la presencia de discinesias es el principal factor asociado con la aparición de trastornos del sueño. En conclusión, este estudio muestra que los factores asociados a la progresión de la EP son los principales factores de riesgo para la aparición de las MNN en nuestra población.

PALABRAS CLAVE: enfermedad de Parkinson, manifestaciones no motoras.

The non-motor manifestations (NMM) are defined as a group of symptoms different from the motor ones in Parkinson's disease (PD) patients. A large group of manifestations are considered as NMM in PD, they include: cognitive disturbances (mild cognitive impairment, executive dysfunction or even dementia), psychiatric manifestations as depressive and anxiety disorders, hallucinations, drug induced psychosis and pathologic gambling; sleep disturbances, including insomnia, REM behavioral disorder, rest- less legs syndrome, diurnal somnolence and also autonomic dysfunction, including mainly constipation, orthostatic hypotension and urinary bladder dysfunction. Skin and visual manifestations are also observed in the PD population. The NMM are a frequent complaint for the patients with PD. Several studies have reported prevalence of NMM between $60 \%$ and $100 \%$ of the PD patients, depending on the methodology used for the evaluation ${ }^{1-10}$.

It has been shown that NMM are a major determinant

'Department of Neurology, Pontificia Universidad Católica de Chile, Santiago, Chile; ${ }^{2}$ Department of Public Health, Pontificia Universidad Católica de Chile, Santiago, Chile; ${ }^{3}$ Centro de Estudios de Trastornos del Movimiento (CETRAM), Universidad de Santiago de Chile.

Received 1 June 2007, received in final form 11 December 2007. Accepted 2 January 2008.

Dr. Carlos Juri - Departamento de Neurología / Pontificia Universidad Católica de Chile - Marcoleta 352 /2 Piso - Santiago - Chile. E-mail: cajuri@gmail.com 
of the quality of life in this population' and dementia is the main risk factor for mortality in the PD. The factors associated with the onset of NMM are still poorly understood. Previous studies have shown that some factors as the presence of predominant axial motor manifestations, as observed in the postural instability and gait disorders (PIGD) subtype of PD or the years of evolution are risk factors for the onset of NMM. But most of these studies evaluate one type of NMM and do not consider the interaction between them.

The aim of this study is to evaluate the prevalence of the more common NMM in a population of PD patients and to determine the features associated with its development.

\section{METHOD}

In a prospective study, consecutive PD patients attended on a movement disorders center were invited to participate. Those who accepted were included and an informed consent, accepted by the local ethical committee, was signed by each subject.

All the patients included were diagnosed with PD according to the London brain bank criteria ${ }^{7}$. Those patients with other neurological diagnosis and those with diabetes mellitus and severe systemic diseases were excluded.

All the included subjects were submitted to a neurological examination and the Unified Parkinson's Disease Rating Scale (UPDRS) motor score, part III, was applied. Also the Hoehn and Yahr scale and the minimental Parkinson's (MMP) test ${ }^{9}$ were administered on the same session and with the patients in the "on" motor state.

For all the subjects we registered the sex, age, age of onset of the PD, drug used for treatment and its doses. Additionally a questionnaire was used to evaluate the presence of motor fluctuations (wearing off and diskynesias) and the occurrence, at least on the last month, of the following: neuropsychiatric manifestations, cognitive disorders, autonomic dysfunction and sleep disorders, as reported by the patient or the caregiver. A semi structured interview was conducted to evaluate the above mentioned manifestations. All the patients were evaluated by one neurologist trained on movement disorders, a total of 2 neurologists did participate in the patients ${ }^{\prime}$ evaluations. A detailed description of the used instruments is given below.

\section{Neuropsychiatric manifestations}

They were indicated as present according to the following items from the neuropsychiatric inventory (NPI) ${ }^{5}$ : Delusions; Hallucinations; Apathy or indifference and Depression or dysphoria. It was considered present if 1 or more positive answers were reported.

\section{Cognitive disorder}

It was classified as a) absent, without clinical evidence of cognitive disorder or b) present, with or without repercussion in the daily life. The classification was according to clinical evaluation and the MMP score. In this test a score below 24 points is suggestive of cognitive disorder?.

\section{Autonomic function}

It was considered to be abnormal if at least 1 of the following manifestations existed: a) constipation: Less than 3 bowel movements per week; b) urinary frequency: urinating 1 or more times each 2 hours on the day or more than 2 times per night; $c$ ) erectile dysfunction and d) symptomatic orthostatic hypotension.

\section{Sleep disorders}

They were considered to be present if insomnia or diurnal somnolence were reported.

To evaluate the relationship between NMM and subtypes of motor manifestations the total UPDRS motor score was divided into 6 motor domains, as previously described ${ }^{8}$. Tremor (scored from 0 to 28), rigidity (scored from 0 to 20), bradykinesia (scored from 0 to 36), facial expression and speech (scored 0 to 4 each one) and axial impairment (scored from 0 to 16). In addition, the motor domains were grouped into 2 subscores that represented predominantly dopaminergic (subscore A: tremor, rigidity, bradykinesia, and facial expression) and nondopaminergic (subscore B: speech and axial impairment) deficiency based on levodopa responsiveness ${ }^{8}$.

All patients were on antiparkinsonian therapy. We calculated the equivalent dose of levodopa based in the following conversion: $100 \mathrm{mg}$ levodopa $=1 \mathrm{mg}$ pergolide $=10 \mathrm{mg}$ bromocriptine $=1.33 \mathrm{mg}$ cabergoline $=100 \mathrm{mg}$ piribedil $=1 \mathrm{mg}$ pramipexole $=4 \mathrm{mg}$ ropinirole.

\section{Statistical analysis}

Data obtained from the files of all patients were collected in a database, and normal distribution was determined using the Kolmogorov-Smirnov test. Groups were defined as with or without each manifestation. Media between groups were compared using chi square or ANOVA as correspond. The correlations were established by means of spearman's rank correlation coefficient. Later a multivariable logistic regression analysis was done to establish the factor (s) that better explained the onset of NMM. The analysis included age of onset, time of evolution of the PD, clinical characteristics of the disease and demographical variables. In those cases with significant multivariable analysis a loess test was applied to determine the linearity of the associations. The statistics software SSPS 10.0 for windows was used. The threshold level for statistical significance was established at $\mathrm{p}<0.05$ ( 2 tails).

\section{RESULTS}

A total of 124 patients were included ( 55 women). Table 1 shows the characteristics of the population. $61.7 \%$ of the patients presented a motor complication. Wearing off in $52.4 \%$ and dyskinesias in $\mathbf{4 7 . 2 \%}$.

The NMM were present in 101 patients (81.5\%). One NMM was present in 25.8\%, 2 NMM in 25\%, 3 NMM in $20.2 \%$ and 4 NMM were present simultaneously in $10.5 \%$. The characteristics of the patients for each NMM are shown in Table 2. 
Neuropsychiatric manifestations were present in $50.8 \%$ of the cases, cognitive disorders were found in $30.6 \%$, autonomic dysfunction was reported by $43.5 \%$ and sleep disorders were reported by as many as $54.8 \%$ of the patients.

The multivariable analysis showed that the years of evolution of PD are a main risk factor for the development of cognitive disorder and autonomic failure. Also the non-dopaminergic score is a risk factor for the cognitive disorder. Dyskinesia appeared as a risk factor for the development of sleep disorders (Table 2).

It is noteworthy that the non-dopaminergic index calculated as indicated from the UPDRS III is correlated with all the NMM, whereas the dopaminergic index is correlated only with neuropsychiatric and cognitive manifestations. The Schwab and England scale was associated with both the dopaminergic $(r=-0.37, p<0.01)$ and non-dopaminergic $(r=-0.74, p<0.001)$ scores indicating the importance of both factors on the PD patient's functionally.

\section{DISCUSSION}

In this ambulatory movement disorder center-based study, we evaluated some characteristics of the PD patients for assessing the role of demographic and clinical features on the development of NMM. We have found that the features associated with the onset of NMM in our population, are mainly those related to the progression of the PD. Around $80 \%$ of our patients have NMM, a high prevalence previously shown by others ${ }^{10-12}$ and a high coexistence of these manifestations was also observed in our patients.

This study shows that neuropsychiatric manifestations and autonomic dysfunction have a similar pattern of risk factors. The years of evolution of the PD and the presence of cognitive dysfunction appear as risk factors for these NMM, probably reflecting a common pathogenic mechanism involved linked to the progression of the neurodegenerative process. A recent study has shown that dementia in PD patients is associated with significantly more impairment in autonomic, depressive and psychotic domains $^{13}$ as is also shown in our study.
Table 1. Characteristics of the study population.

\begin{tabular}{lc}
\hline Men /Women & $69(55.6) / 55(44.4)$ \\
\hline Hoehn \& Yahr stage(\%): I / II & $18(14.5) / 13(10.5)$ \\
III / IV & $78(62.9) / 15(12.1)$ \\
Patients on levodopa therapy (\%) & $115(92.7)$ \\
Patients on dopaminergic agonists (\%) & $53(42.7)$ \\
Age at study & $66.1 \pm 10.9$ \\
Age at disease onset & $58,0 \pm 11.6$ \\
Years of evolution & $8.1 \pm 5.2$ \\
Total UPDRS III (range 0-108) & $27.6 \pm 14.7$ \\
Tremor (range, 0-28) & $2.3 \pm 3.6$ \\
Rigidity (range, 0-20) & $6.2 \pm 3.7$ \\
Bradykinesia (range, 0-36) & $13.1 \pm 6.2$ \\
Axial impairment (range, 0-16) & $6.1 \pm 4.4$ \\
Levodopa dosage, mg & $713 \pm 484$ \\
\hline
\end{tabular}

Values are expressed as media \pm SD or number of cases (\%).

Additionally, we report here that the axial impairment (as reflected by the non dopaminergic index) is related to the cognitive dysfunction. A previous report of our group showed a similar result in depression associated with $\mathrm{PD}^{3}$. These findings agree with the idea that the axial manifestations are an expression of the involvement of non dopaminergic systems, which could also be reflected as a NMM. Previous studies have shown that the postural instability gait disorders (PIGD) motor subtype of PD has a higher risk of dementia ${ }^{2,13}$, a finding that is similar to our results.

The sleep disturbances are related in our multivariate analysis only to the dyskinesias, probably reflecting both the advance of the disease and a higher dose of levodopa in this group of subjects. These factors has been previously found associated with sleep related problems in patients with $\mathrm{PD}^{6}$.

Our data emphasized the impact of the NMM on the functionality of the PD subjects as shown by that high. Association between the Schwab and England scale and

Table 2. Features associated with the development of non motor manifestations (multivariable analysis).

\begin{tabular}{lccc}
\hline Manifestation & Features & OR $(95 \% \mathrm{Cl})$ & $\mathrm{p}$ Value \\
\hline Neuropsychiatric & Cognitive disorder & $3.88(1.67-9.18)$ & 0.0020 .024 \\
& Years of evolution & $1.09(1.01-1.18)$ & \\
Cognitive disorder & NP & $3.5(1.21-7.32)$ & 0.05 \\
& Non-dopaminergic score & $1.16(1.07-1.43)$ & 0.02 \\
Autonomic dysfunction & Cognitive disorder & $3.36(1.41-8.02)$ & 0.0060 .001 \\
& Years of evolution & $1.18(1.08-1.29)$ & \\
Sleep disorders & Diskynesias & $2.95(1.39-6.23)$ & 0.005 \\
\hline
\end{tabular}

NP, neuropsychiatric manifestations; OR, odds ratio. 
the existence of NMM as shown previously by others'. PD patients are very frequently affected by NMM and these manifestations are a main determinant of the quality of life in these patients. The etiology of NMM has been linked to the neurodegenerative process itself, to the drugs used for the treatment, to social and ambient factors, between others.

It has been recognized that the neurodegenerative process in PD extends to regions of the brain outside the basal ganglia and to neurotransmitter systems others than the dopaminergic. The locus coeruleus (norepinephrine), the nucleus basalis of Meynert (acetylcholine), the raphe nucleus (serotonin) and the pedunculopontine nucleus (PPN) are affected in the PD patients since early stages of the disease. A complex interaction between these deficits and the dopaminergic deficiency could be the origin of most of the $\mathrm{NMM}^{4}$. With the advance of the neurodegenerative process the cortical regions are affected, determining the increase of neuropsychiatric and cognitive disturbances in these patients.

Our study have some limitations as the lack of a valid instrument for the screening of all these manifestations, also the data are based on a unique evaluation, what limits the precise determination of the factors associated with the onset of each NMM. With all we think than our results contribute to improve our understanding of the NMM in the PD patients.

\section{REFERENCES}

1. The Global Parkinson's Disease Survey (GPDS) Steering Committee Factors impacting on quality of life in Parkinson's disease: results from an international survey. Mov Disord 2002;17:60-67.

2. Burn DJ, Rowan EN, Allan LM, et al. Motor subtype and cognitive decline in Parkinson's disease, Parkinson's disease with dementia, and dementia with Lewy bodies. J Neurol Neurosurg Psychiatry 2006;77: 585-589.

3. Chana-Cuevas P, Juri-Claverias C, Alburquerque D, Soto-Olmedo MJ, Benavides-Canales O. [Risk factors associated to the presentation of episodes of major depression in a population of outpatients with Parkinson's disease]. Rev Neurol 2006;42:521-524.

4. Chaudhuri KR, Martinez-Martin P, Schapira AH, et al. International multicenter pilot study of the first comprehensive self-completed nonmotor symptoms questionnaire for Parkinson's disease: the NMSQuest study. Mov Disord 2006;21:916-923.

5. Cummings JL, Mega M, Gray K, et al. The neuropsychiatric inventory: comprehensive assessment of psychopathology in dementia. Neurology 1994;44:2308-2314.

6. Happe S, Ludemann P, Berger K.The association between disease severity and sleep-related problems in patients with Parkinson's disease. Neuropsychobiology 2002;46:90-96.

7. Hughes AJ, Daniel SE, Kilford L, Lees AJ.Accuracy of clinical diagnosis of idiopathic Parkinson's disease: a clinico-pathological study of 100 cases. J Neurol Neurosurg Psychiatry 1992;55:181-184.

8. Levy G, Louis ED, Cote L, et al. Contribution of aging to the severity of different motor signs in Parkinson disease. Arch Neurol 2005;62:467-472.

9. Parrao-Diaz T, Chana-Cuevas P, Juri-Claverias C, Kunstmann C, TapiaNunez J. [Evaluation of cognitive impairment in a population of patients with Parkinson's disease by means of the mini mental Parkinson test]. Rev Neurol 2005;40:339-344.

10. Raudino F. Non motor off in Parkinson's disease. Acta Neurol Scand 2001;104:312-315.

11. Shulman LM, Taback, RL, Rabinstein AA., Weiner WJ. Non-recognition of depression and other non-motor symptoms in Parkinson's disease. Parkinsonism Relat Disord 2002;8:193-197.

12. Sullivan KL, Ward CL, Hauser RA., Zesiewicz TA. Prevalence and treatment of non-motor symptoms in Parkinson's disease. Parkinsonism Relat Disord 2006;13:545.

13. Verbaan D, Marinus J, Visser M et al. Cognitive impairment in Parkinson's disease. J Neurol Neurosurg Psychiatry 2007;78:1182-1187. 